\title{
Australian Journal of

\section{Development of a mini core collection from Sri Lankan traditional rice for flowering time variation}

\author{
Elpitiya Udari Uvindhya Rathnathunga ${ }^{1}$, Gamini Senanayake ${ }^{2}$, Nimal Dissanayake ${ }^{3}$, Saman \\ Seneweera $^{4}$ and Sudarshanee Geekiyanage ${ }^{2 *}$
}

\author{
${ }^{1}$ Board of Study in Agriculture, Faculty of Graduate Studies, University of Ruhuna, Matara, Sri Lanka \\ ${ }^{2}$ Department of Agricultural Biology, Faculty of Agriculture, University of Ruhuna, Mapalana, Kamburupitiya, \\ Sri Lanka \\ ${ }^{3}$ Address during the research period: Rice Research and Development Institute, Bathalagoda, Sri Lanka \\ ${ }^{4}$ Centre for Systems Biology, University of Southern Queensland, Toowoomba, QLD 4350, Australia
}

*Corresponding author: sudarshanee@agbio.ruh.ac.lk

\begin{abstract}
Sri Lankan traditional rice germplasm (Oryza sativa indica) consists of a wide variety of morphology and days to flowering (DF). The objective of this research was to develop a mini core collection representing the DF variation of the total collection. Three hundred and eighty four rice accessions from 53 Sri Lankan traditional rice varieties were evaluated for morphological and flowering time variation. The experiment was carried at Rice Research and Development Institute, Bathalagoda, Sri Lanka during the late short day season (Maha), 2012/2013.Three hundred and forty five accessions flowered and 39 accessions did not flower during the experimental period of 210 days. Two principal component analyses (PCA) were performed and subsequently 2 dendograms were developed for flowered and not flowered accessions. Sixty eight percent of total observed variation was explained through 6 principal components (PC's) by DF and fourteen quantitative morphological characters of 345 flowered accessions. Seventy nine percent of total observed variation of not flowered 39 accessions was explained through 4 PC's by 9 quantitative morphological characters. Ninety accessions were selected from 2 dendograms for development of a mini core collection; out of which 85 accessions represented flowered accessions based on minimum and maximum DF variation in each cluster of the dendogram. Five randomly selected accessions represented each cluster of not flowered accessions. Minimum and maximum DF values of both total collection and mini core collection were 56 and 189 days, respectively. Average DF of total flowered collection and mini core collection was $79.16 \pm 0.95$ and $87.95 \pm 3.1$, respectively. A similar trend in the regression relationship between DF and plant height and, DF and leaf length of the leaf prior to flag leaf was observed in total flowered collection and mini core collection, indicating the representation of mini core collection for flowering time variation.
\end{abstract}

Keywords: correlation, days to flowering, Oryza sativa, morphological characters, varietal diversity. Abbreviations:

AD - Anderson-Darling statistic

CD - Culm diameter at maturity

CL - Culm length at maturity

$\mathrm{CN}$ - Culm number at maturity

DF - Days to flowering

FAO - Food and Agriculture Organization of the United Nations

GL - Grain length at maturity

GW - Grain width at maturity

IBM - International Business Machines

IRRI - International Rice Research Institute

LiL - Ligule length at maturity

LL - Leaf length at maturity

$\mathrm{LN}$ - Leaf number at maturity

\section{Introduction}

Rice is the most important cereal crop in Sri Lanka as $12 \%$ of lands are under rice approximately accounting for 3.6 million metric tons of rice production (Food and Agriculture Organization of the United Nations (FAO) Rice Market Monitor, 2014). Though Sri Lanka is a selfsufficient country with rice production, almost 1 million tons of reduction in rice was observed in 2014 due to
LW - Leaf width at maturity

PC's - principal components

PCA - Principal Component Analysis

PGRC - Plant Genetic Resources Center,

$\mathrm{PH}$ - Plant height at maturity

PL - Panicle length at maturity

PW - Panicle weight at maturity

RL - Root length at maturity

RRDI - Rice Research and Development Institute

SAS - Statistical Analysis System software

SPSS - Statistical Package for the Social Sciences software

SW - Shoot weight at maturity

severe drought conditions. Unfavorable climatic, environmental and growing conditions and, reduction of land use could adversely affect the rice production. Therefore, it is a necessity to increase the production by enhancing the genetic diversity though breeding new varieties adapted to future challenges of climate change. Natural altitude and latitude of island Sri Lanka provides 
diverse climatic zones which lead to unpredictable year to year variation of the onset of rainy season and less than an hour of maximum day length difference between Yala and Maha seasons (Herdt and Capule, 1983; Irangani and Shiratake, 2013; Yoshida, 1983). The Southwest Monsoon (Yala) prevails from May to September while the Northeast Monsoon (Maha) lasts from December to February (Manawadu and Fernando, 2008 ). Dry zone (of $<1,750 \mathrm{~mm}$ of annual rainfall), wet zone (of $>2,500 \mathrm{~mm}$ of annual rainfall) and intermediate zone (of 1,750 - 2,500 $\mathrm{mm}$ of annual rainfall) of diverse rainfall distribution in addition to elevation and temperature deviation leads to 46 agro-ecological subregions (Supplementary fig 1) (Chithranayana and Punyawardena, 2008; Punyawardena, 2004).

Ecological diversity may contribute to the morphological and flowering time variation of Sri Lankan rice germplasm, which lead to Short term and Long term varieties, photoperiod sensitive and insensitive varieties and 'Period fixed' and 'Date fixed' varieties (Chandraratna, 1964; Irangani and Shiratake, 2013; Yoshida, 1983). Later new improved varieties with desired plant type, photoperiod insensitivity, high yield, short maturity, good grain quality and adaptability were promoted by Rice Research and Development Institute (RRDI), Sri Lanka and other research stations (Irangani and Shiratake, 2013; Herdt and Capule, 1983; Wang et al., 2012). However, the agronomic traits of Sri Lankan traditional rice for adaptation to climate change such as photoperiod sensitivity, rapid inter-node elongation, drought tolerance, submergence tolerance, disease and pest resistance and grain quality characters of fragrance, grain length and pericarp color could be incorporated in future breeding programs (Chandraratna, 1964; Wijerathna et al., 2012). Chandrarathna (1954) concluded that Heenati, Vellai ilankalaya and Devaraddari as period fixed (DF is not affected by the sowing date) varieties and Kohu ma wee as a date fixed variety (DF is affected by the sowing date) (Chandraratna, 1964). Short term Sri Lankan rice varieties such as Hetada wee, Heenati, Dahanala, Kokkali, Suwadel, Pachchaperumal, Kunni murunga, Kuru wee, Rathadal and Rath thambiliya are photoperiod insensitive, which flower at any time of the year after vegetative phase. Above varieties are suitable for the drought conditions and multiple cropping systems (Irangani and Shiratake, 2013; Yoshida, 1981). Highly photoperiod sensitive varieties of Maha ma wee, Bata ma wee, Dik wee, Hata paduru wee, Mada al, Devaraddari, Madatawalu, Murungakayam, Vellai ilankalaya, Hondarawala, Gangala, Baruwel, Masuran, Sulai and Handiran are long term, floating varieties which are suitable for deep water paddy fields and delayed rainy seasons (Chandraratna, 1964; Irangani and Shiratake, 2013; Vergara and Chang, 1985; Yoshida, 1981). The photoperiod sensitivity of rice varieties can influence the vegetative growth duration and flowering which could even lead to no flowering beyond a critical photoperiod (Vergara and Chang, 1985; Yoshida, 1981). Thavalu, Kurkardppan and Goda heenati are the most submergence tolerant varieties (Pessarakli, 2010). High salt tolerant traditional rice varieties were identified by De Costa et al. (2012). Gallagher (1988) identified brown plant hopper resistant genes in Rath heenati and Baba wee. Oryza sativa is distributed among wide geographical areas in Asian continent (Khush, 1997). According to Lu et al. (2009), the most significant genetic differentiation in Asian cultivated rice is the Oryza indica, Oryza japonica differentiation. It represents the development of 2 ecotypes in distinct geographic locations which are named as sup-species (Kato et al., 1928) Differentiation had led to differences in agronomy and physiological - biological features in 2 sub-species (Matsuo, 1952). Sri Lankan rice accessions comprised of morphological characters listed under Oryza indica sup group (Chandraratna, 1964). Morphology of plant and grain characters are important in identification of above sub species (Chang and Bardenas, 1965): Oryza sativa indica is characterized with broad light green leaves, tall plant structure, mostly being awneless, thin and short hairs on lemma and palea, easy shattering and sensitivity to photoperiod in contrast to Oryza sativa japonica with dark green leaves, short plant structure, being awnless to long awned, dense and long hairs on lemma and palea, low shattering and low sensitivity to photoperiod. Oryza sativa jovanica exhibits intermediate characteristics of those two subspecies; broad light green leaves, tall plant structure, being awnless or long awned, long hairs on lemma and palea, low shattering and low sensitivity to photoperiod. An effective identification method for Oryza sativa indica and Oryza sativa japonica was introduced by $\mathrm{Lu}$ et al. (2009) based on polymorphisms of insertions and deletions (InDel) in DNA fragments of entire genome of Oryza sativa indica and Oryza sativa japonica genotypes. Information on genetic differentiation of Oryza sativa indica and Oryza sativa japonica rice could be useful in studies on origin and evolution of rice adapted to variable environments in Asia.

Wide collections of rice, wild relatives and land races from different geographical regions of the world are conserved at International Rice Research Institute (IRRI) for maintenance of genetic diversity, avoidance from extinction of genetic resources, utilization in rice breeding programmes and for evolutionary studies (IRRI, 1991). Sri Lankan rice germplasm is considered to be Oryza sativa sub species indica. Approximately 2000 rice accessions with wide morphological and potential genetic diversity are conserved at Plant Genetic Recourses Center (PGRC), Sri Lanka. In 1960's Sri Lankan traditional rice germplasm had been explored from all over the country. Collected accessions were deposited in IRRI gene bank. Later, a replica of the whole collection had been brought back to Sri Lanka. However, passport data are not completely available at PGRC, Sri Lanka. As a result exact exploration sites are not known. The varieties with very similar characters from different geographical locations of Sri Lanka were collected and preserved at PGRC under same variety name in different accession numbers (Supplementary fig1, Supplementary table 1 and 2). We have morphologically characterized a part of Sri Lankan rice germplasm. There is a necessity of preparation of a mini core collection which represents the above broad genetic basis with minimum redundancies and minimum losses of original diversity as reported by Studnicki et al. (2013). A mini core collection can be utilized for various aspects including plant breeding, conservation, identification of varieties against diseases and pests and, for molecular genetic studies (Ren et al., 2012; Santra et al., 2013; Zhang et al., 2012). Development of a representative diversity research set is an urgent need for Sri Lankan traditional rice for its utilization in breeding programs. The large collection of Sri Lankan traditional rice germplasm comprised of the morphological and flowering time variation with adaptability to diverse agro-ecological regions in relatively small geographical territory of Sri Lanka is difficult to be handled in 
breeding programs. Therefore, for the first time in Sri Lanka we developed a mini core collection from a part of total conserved Sri Lankan traditional rice germplasm in order to continue our next studies on genetic basis for wide flowering time variation within one photoperiod growing season (Short day or Long day) and between two seasons. To determine the extreme photoperiod sensitive accessions we planned our experiment 3 months after the onset of short day season which resulted in non-flowering in some extremely sensitive rice accessions. Our objective was to develop a mini core collection which represents the Sri Lankan traditional rice germplasm (Oryza sativa indica) on the basis of flowering time and morphological variation.

\section{Results}

\section{Principal Component Analysis (PCA)}

Three hundred and forty five accessions had flowered and thirty nine accessions had not flowered during the experimental period of 210 days. Two separate PCAs were performed for flowered accessions and notflowered accessions. Sixty eight percent of total observed variation was explained by six PC's for the flowered accessions. PC1 included plant stem length characters of Plant height at maturity $(\mathrm{PH})$ and Culm length at maturity (CL) with scores of 0.890 and 0.894 explaining $13.4 \%$ of the total observed variance. Leaf number at maturity (LN), Culm number at maturity $(\mathrm{CN})$ and Shoot weight at maturity (SW) scored $0.763,0.669$ and 0.789 respectively representing plant vigor in $\mathrm{PC} 2$ explaining $12.7 \%$ of the total observed variance. DF $(0.821)$ and leaf characters of Leaf length at maturity (LL) (0.822) and Leaf width at maturity (LW) (0.614) were included in PC3 explaining $12.1 \%$ of the total observed variance. The Ligule length at maturity (LiL), Culm diameter at maturity (CD) and Panicle length at maturity (PL) respectively scored $0.755,0.601$ and 0.603 in PC4 explaining $11.5 \%$ of the total observed variance. Root length at maturity (RL) scored 0.805 while Panicle weight at maturity (PW) scored - 0.642 in PC5 explaining $9.3 \%$ of the total observed variance. Grain characters of Grain length at maturity (GL) (0.777) and Grain width at maturity $(\mathrm{GW})(0.675)$ were included in PC6 contributing to $9.1 \%$ of the total observed variance (Table 1).

In not flowered accessions, $79 \%$ of total observed variation was explained by four PC's. PC1 explained $25.4 \%$ of $\mathrm{LiL}$ and $\mathrm{CD}$ scores of 0.883 and 0.862 respectively. $\mathrm{LN}, \mathrm{CN}$ and $\mathrm{SW}$ scores of $0.663,0.630$ and 0.929 represented plant vigor in PC2 explaining 22.2\% of variance. LL (0.867) and PH (- 0.716) explained $16.8 \%$ of variance in PC3. RL scored 0.900 in PC4 explaining $14.8 \%$ of variance (Table 2 ).

\section{Correlation analysis among days to flowering and morphological characters}

The correlation analysis revealed that there were significant correlations among DF and morphological characters. Among flowered accessions, DF positively correlated with LL $(+0.574)$ while $\mathrm{LN}$ with $\mathrm{CN}(+0.324)$ and SW (+0.435). LL correlated with LW (+0.324). PH correlated with CD $(+0.343)$. CD correlated with PL $(+0.330)$. CN correlated with SW $(+0.389)$ and SW correlated with $\mathrm{PW}(+0.342)$. Among not flowered accessions, PH correlated with $\mathrm{CD}(+0.336), \mathrm{LiL}$ $(+0.361)$ and $\mathrm{SW}(+0.334)$ while $\mathrm{CD}$ correlated with $\mathrm{LiL}$
$(+0.661)$ and RL (+0.314). SW correlated with $\mathrm{LN}$ $(+0.505)$ and $\mathrm{CN}(+0.539)$ (Supplementary table 3 and 4).

\section{Cluster analysis}

Two separate dendograms were developed for flowered accessions and not flowered accessions (Fig 1 and 2). Forty clusters were identified at the rescale distance of 5 from the dendogram developed using the flowered accessions while five clusters were selected at the rescale distance of 15 from the dendogram developed using not flowered accessions (Fig 1 and 2; Supplementary table 1 and 2).

One or a few accessions with minimum and maximum DF within each cluster were considered to represent 85 accessions from the set of flowered accessions. Five accessions were randomly selected as one from each cluster of the dendogram developed using not-flowered accessions. All together the mini core collection comprised of 90 Sri Lankan traditional rice accessions (Supplementary table 1 and 2).

\section{Comparison of total collection and mini core collection through descriptive statistics and regression analysis}

Minimum and maximum DF values of both total collection and mini core collection were 56 and 189 days respectively. Average DF values were $79.16 \pm 0.95$ and $87.95 \pm 3.1$ days in total collection and mini core collection respectively. In distribution curves of DF for total collection and mini core collection, standard deviation was 17.68 and 28.62 respectively (Fig 3. A). Both DF of total collection and DF of mini core collection were not normally distributed (Fig 3. B).

Significant regression models could be developed for the relationship between DF and PH, and DF and LL which indicated the representation of the effect of DF in 345 flowered traditional rice accessions in the selected 85 accessions of mini core collection. The regression equation of $\mathrm{PH}$ versus $\mathrm{DF}$ is $\mathrm{PH}=120.5+0.2340 \mathrm{DF}$ $(\mathrm{R} 2=4.9 \%, \mathrm{p}=0.000)$ for flowered accession of total collection and $\mathrm{PH}=120.5+0.2340 \mathrm{DF}(\mathrm{R} 2=5.9 \%, \mathrm{p}=$ $0.026)$ for selected accessions. The regression equation of $\mathrm{LL}$ versus $\mathrm{DF}$ is $\mathrm{LL}=34.39+0.2477 \mathrm{DF}(\mathrm{R} 2=33.0$ $\%, \mathrm{p}=0.000)$ for flowered accession of total collection and $\mathrm{LL}=38.8+0.1848 \mathrm{DF}(\mathrm{R} 2=35.6 \%, \mathrm{p}=0.000)$ for selected accessions (Fig 4).

\section{Varietal diversity of total collection of 384 Sri Lankan traditional rice accessions}

Three hundred and eighty four rice accessions listed under 53 varieties comprised of one accession to 28 accessions were chosen to classify the varietal assortment of Sri Lankan traditional rice germplasm (Table 3). Pictures of seed and the pericarp of one accession from each cluster of the dendogram of flowered accessions and not-flowered accessions are presented (Supplementary table 1 and 2). Among them, only seeds of Hondarawala 4243, Ma wee 6702, 6699 and 3683 and Maha ma wee 8696 had awns.

Lemma and palea colors varied among accessions. Representative 45 seeds from the dendograms indicated in supplementary table 1 and 2: Lemma and pelea colours of 9 straw, 8 gold furrows on straw background, 5 brown furrows on straw background, 2 brownish black, 2 yellowish brown, 8 brown furrows on gold background, 4 black spots on straw background, 2 
Table 1. Expressed variation of principal component analysis of flowered traditional rice accessions and the expression morphological traits in each component.

\begin{tabular}{lccccc}
\hline $1^{\text {st }} \mathrm{PC}$ & $2^{\text {nd }} \mathrm{PC}$ & $3^{\text {rd }} \mathrm{PC}$ & $4^{\text {th }} \mathrm{PC}$ & $5^{\text {th }} \mathrm{PC}$ & $6^{\text {th }} \mathrm{PC}$ \\
\hline $13.362 \%$ & $12.671 \%$ & $12.127 \%$ & $11.510 \%$ & $9.260 \%$ & $9.111 \%$ \\
\hline $\mathrm{PH}(0.890)$ & $\mathrm{LN}(0.763)$ & $\mathrm{DF}(0.821)$ & $\mathrm{LiL}(0.755)$ & $\mathrm{RL}(0.805)$ & $\mathrm{GL}(0.777)$ \\
$\mathrm{CL}(0.894)$ & $\mathrm{CN}(0.669)$ & $\mathrm{LL}(0.822)$ & $\mathrm{CD}(0.601)$ & $\mathrm{PW}(-.642)$ & $\mathrm{GW}(0.675)$ \\
& $\mathrm{SW}(0.789)$ & $\mathrm{LW}(0.614)$ & $\mathrm{PL}(0.603)$ & &
\end{tabular}

Abbreviations of quantitative morphological characters: Days to flowering (DF), Plant height at maturity (PH), Culm length at maturity (CL), Culm number at maturity (CN), Culm diameter at maturity (CD), Shoot weight at maturity (SW), Leaf number at maturity (LN), Leaf length at maturity (LL), Leaf width at maturity (LW), The Ligule length at maturity (LiL), Panicle length at maturity (PL), Root length at maturity (RL), Panicle weight at maturity (PW), Grain length at maturity (GL), Grain width at maturity (GW).

brownish gold furrows on gold background, 2 brownish black furrows on straw background and 3 brown furrows on yellowish background are detected.

Variation of pericarp colours of the representative seed collection dispersed within 2 off white, 4 white, 12 light brown, 12 brown, 7 red, 2 purple, 1 off white pericarp with black apiculus, 2 red pericarp with white strip, 1 off white pericarp with white strip and black apiculus and 2 brown pericarp with white strip and the black apiculus (Supplementary table 1 and 2).

\section{Discussion}

\section{Genetic basis for flowering initiation}

Among the 384 accessions, only 345 accessions flowered during the experimental period while the rest 39 accessions remained in the vegetative phase. Environment factors affect flowering time in rice (Vergara and Chang, 1985; Yoshida, 1983): Photoperiod and temperature are the most important factors among them. Occurrence of flowering only in a group of accessions from the collection during the late Maha season (the onset of non-inductive season with long days) may indicate the differences in genetic factors responsive to photoperiodic flowering among flowered and not flowered accessions. Two growing seasons in Sri Lanka (Yala and Maha) are characterized by photoperiod and temperature differences, in addition to rainfall differences (De Costa, 2012; Irangani and Shiratake, 2013; Manawadu and Fernando, 2008).This experiment was studied at the onset of non-inductive photoperiod to exploit the maximum flowering variation due to photoperiod sensitivity for future use in photoperiod experiments mainly. Sri Lankan traditional rice is known to be photoperiod sensitive; hence some varieties, such as Ma wee are grown only during short day season (Maha) (Chandraratne, 1964; Irangani and Shiratake, 2013).

\section{Association of evaluated characters in Principal Component Analysis}

Positive associations between plant architectural traits (SW, LN and $\mathrm{CN}$ ) were observed in $\mathrm{PC} 2$ of both flowered and not flowered PCAs. Fageria (2014) had reported similar observations as well. Genes involved in controlling $\mathrm{CN}$ is also involved in the shoot branching and panicle branching (Lin, et al., 2012; Xu, et al., 2012). In PC4 of flowered accessions and PC1 of not- flowered accessions consisted of relationships between LiL and, CD. Ligule is a feature of genus Oryza and $l g$ is the single recessive allele responsible for ligule-less rice. Possibility on the presence of LiL could be associates with CD of rice plant (Chandraratna, 1964). Although there are reports on the alleles controlling DF having pleiotropic effect on $\mathrm{PH}$ we have not detected direct association between DF and PH. The observation of DF combined with leaf characters in PC3of PCA performed using flowered accessions. Grain characters were explained in PC6 of PCA of flowered accessions (Table 1 and 2).

\section{Correlation analysis among days to flowering and morphological characters}

In this study, DF only positively correlated with LL for the flowered rice germplasm. Out of 50 morphological, physiological and disease resistant traits, 33 traits including LL were significantly correlated with DF in temperate japonica rice (Hori et al., 2012). A significant correlation was observed for DF with PL and PW (Ashfaq et al., 2012) while $\mathrm{CN}$ and grain yield was found to be positively correlated for 14 red rice genotypes of Indian rice by Sanghera et al. (2013). CD correlates with PL and SW correlates with PW for the PCA of flowered accessions in this study. The observed relationships of DF, plant structure and yield components would indicate that responsible genes may be linked and the pattern of their expression would be common for tested Sri Lankan rice accessions (Supplementary table 3 and 4).

\section{Development of a mini core collection}

Wide flowering time variation and morphological variation of Sri Lankan rice germplasm would be useful in genetic studies for breeding. In this study, DF varied from 56 to $210+$ days within the experimental period of 210 days. Plant senescence had occurred after 210 days which happened to terminate the experiment. Our ultimate objective in the future is to study the morphological and yield responses of Sri Lankan rice for different photoperiodic conditions. The large collection of Sri Lankan traditional rice germplasm comprised of the morphological and flowering time variation with adaptability to diverse agro-ecological regions in relatively small geographical territory of Sri Lanka is difficult to be handled in breeding programs. Therefore, for the first time in Sri Lanka we developed a mini core collection from part of total Sri Lankan traditional rice germplasm in order to continue our next studies on genetic base for wide during the variation within one photoperiod growing season (Short day and Long day) and between two seasons. To determine the extreme photoperiod sensitive accessions we planned our experiment 3 months after the onset of short day season which resulted in non-flowering in some extremely sensitive rice accessions. Representation of virtual flowering time variation of Sri Lankan traditional rice was the purpose of considering two dendograms of the flowered dendogram and the not flowered dendogram (Fig 1 and 2). Studnicki et al. (2013) developed a core 

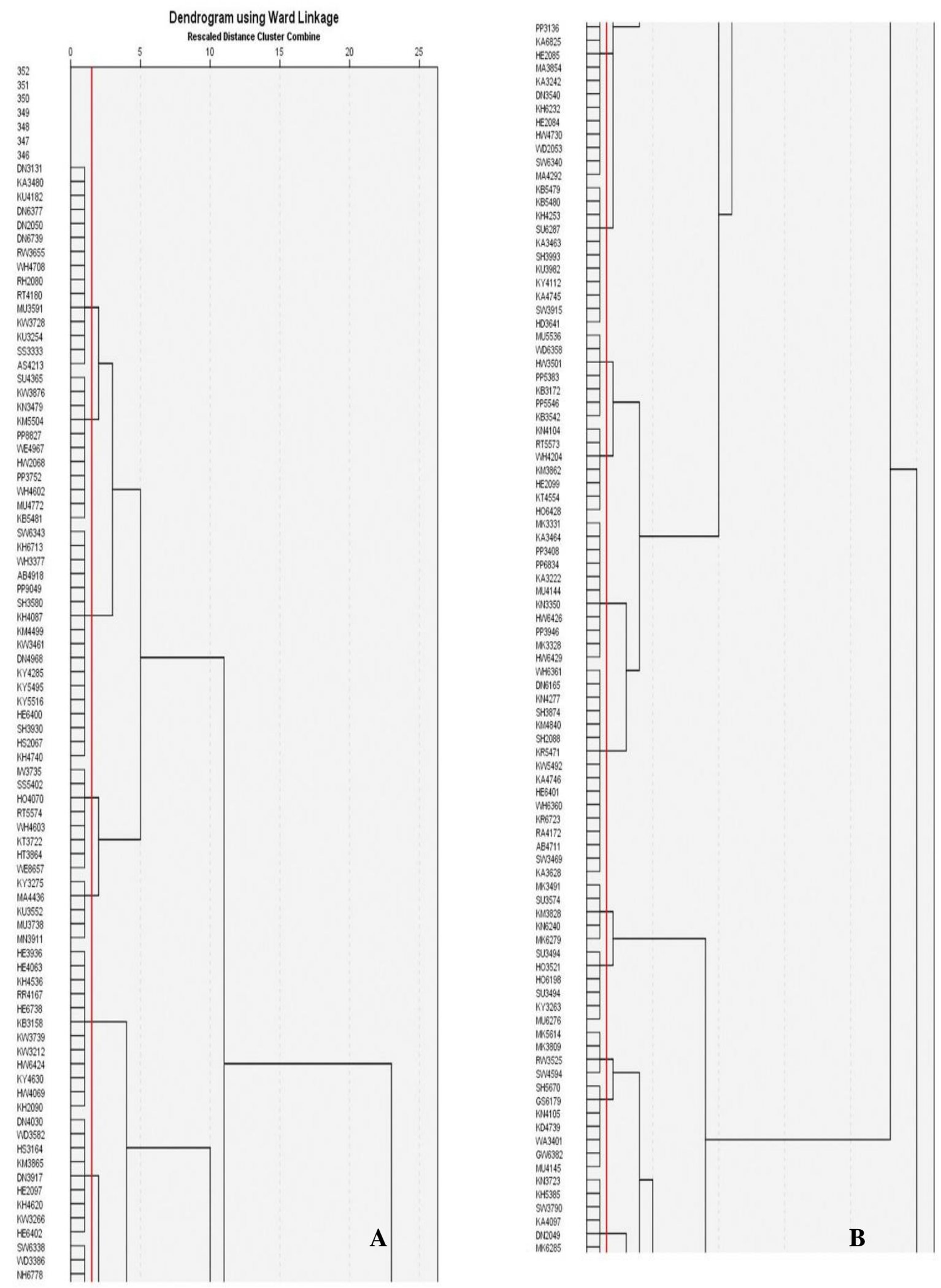


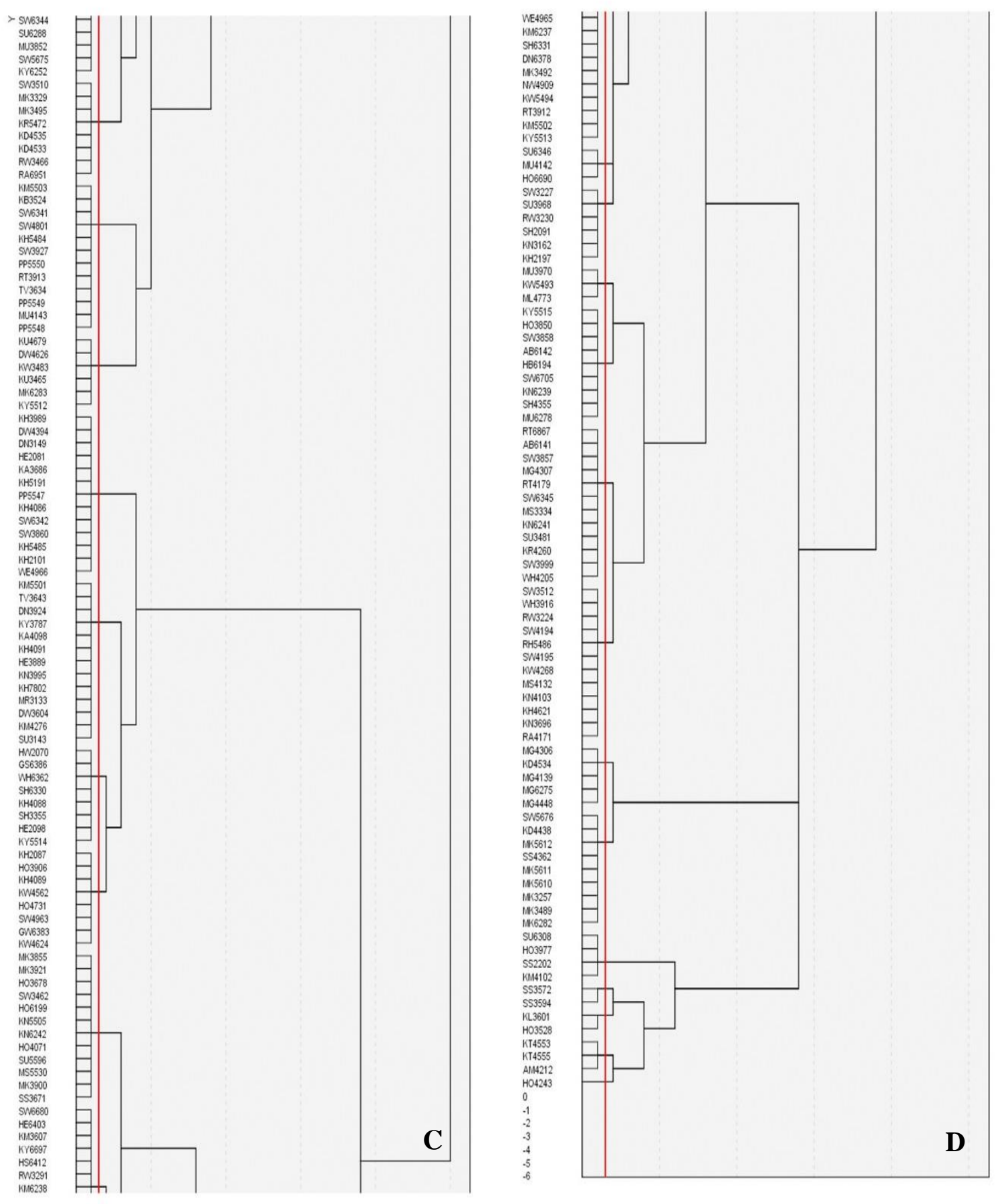

Fig 1. Dendogram of the accessions which derived through Ward's linkage Cluster Analysis based on fifteen morphological traits of flowered accessions. A, B, C and D were the respective parts of the derived dendogram.

The red line indicates the demarcation of rescale distance which uses to select the 40 clusters for mini core collection, cluster numbers and accessions included detailed Table 4 and 5.

Abbreviations of variety names mentioned in the figure: Ahamba (AM), Akuramboda (AB), Alagu samba (AS), Dahanala (DN), Duru wee (DW), Gires wee (GS), Goda wee (GW), Heen dik wee (HD), Heenati (HE), Heras (HS), Herath banda (HB), Hetada wee (HW), Hodarawala (HO), Ismail wee (IW), Kaharamana (KR), Kalu bala wee (KB), Kalu handiran (KD), Kalu heenati (KH), Kalu wee (KW), Karayal (KA), Kiri murunga (KM), Kiri naran (KN), Kotteyaran (KY), Kuru ma wee (KE), Kuru wee (KU), Kurulu wee (KL), Kurulu thuda (KT), Ma wee (MW), Mada al (MA), Maha ma wee (MM), Manikkam (MN), Masuran (MS), Molligoda (MG), Mudukiriyal (MU), Muhudu rella (ML), Murunga (MR), Murungakayan (MK), Niyan wee (NW), Pachchaperumal (PP), Ranruwan (RR), Rata wee (RW), Rath al (RA), Rathu heenati (RH), Rathu wee (RT), Sudu heenati (SH), Sudu wee (SW), Suduru samba (SS), Sulai (SU), Thavalu (TV), Wanni dahanala (WD), Wanni heenati (WA), Weda heenati (WE), Weli handiran (WH). 
Table 2. Expressed variation of principal component analysis of not flowered traditional rice accessions and the expression morphological traits in each component.

\begin{tabular}{llll}
\hline $1^{\text {st }} \mathrm{PC}$ & $2^{\text {nd }} \mathrm{PC}$ & $3^{\text {rd }} \mathrm{PC}$ & $4^{\text {th }} \mathrm{PC}$ \\
\hline $25.399 \%$ & $22.214 \%$ & $16.773 \%$ & $14.799 \%$ \\
\hline $\operatorname{LiL}(0.883)$ & LN $(0.663)$ & LL $(0.867)$ & RL $(0.900)$ \\
CD $(0.862)$ & CN $(0.630)$ & PH $(-0.716)$ & \\
& SW $(0.929)$ & & \\
\hline
\end{tabular}

Abbreviations of quantitative morphological characters: Plant height at maturity (PH), Culm number at maturity (CN), Culm diameter at maturity (CD), Shoot weight at maturity (SW), Leaf number at maturity (LN),Leaf length at maturity (LL), Root length at maturity (RL).

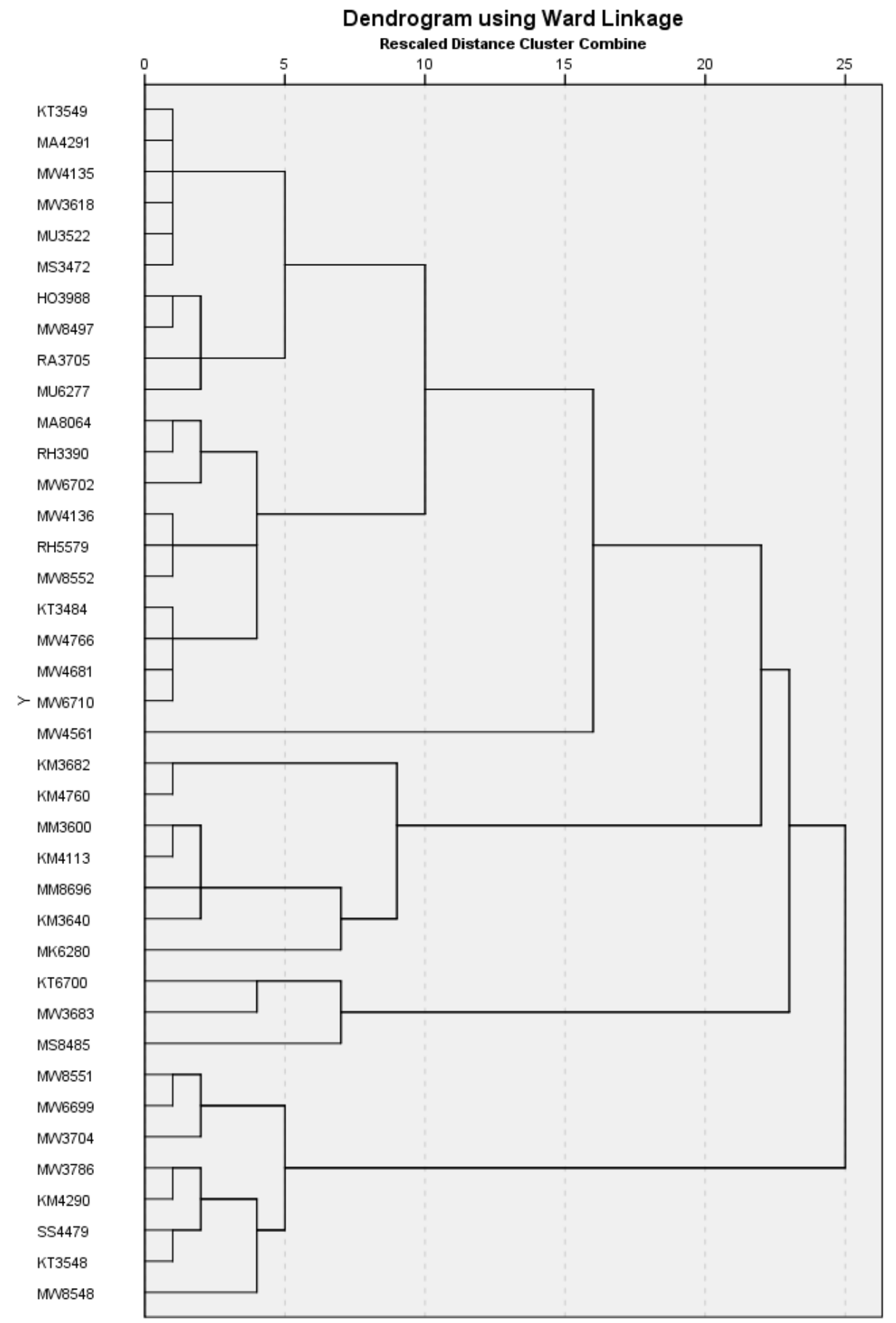

Fig 2. Dendogram of the accessions which derived through Ward's linkage Cluster Analysis based on nine morphological traits of not flowered accessions.

Abbreviations of variety names mentioned in the figure: Hodarawala (HO), Kiri murunga (KM), Kuru ma wee (KE), Kurulu thuda (KT), Ma wee (MW), Mada al (MA), Maha ma wee (MM), Masuran (MS), Murungakayan (MK), Rath al (RA), Rathu heenati (RH), Suduru samba (SS), 
collection to represent a whole population based on random sampling method. In this study, accessions with extreme flowering time were selected following Studnicki et al. (2013). However, instead of selecting random accessions, 2 extremes of flowered accessions were selected from each cluster expecting flowering time variation from potential genetically distinct clusters. Eighty five accessions were selected considering the minimum and maximum DF of accessions within each cluster including Thavalu 3643, Herath banda 6194, Hondarawala 6198, Hondarawala 6690, Mudukiriy al 6276 and Sulai 3494 to represent flowering time variation of Sri Lankan traditional rice in the mini core collection. All Ma wee (16), Maha ma wee (2) and Kuru ma wee (5) accessions did not flower along with some other accessions from Kurulu thuda (4), Mada al (2), Mudukiriy al (2), Masuran (2), Murungakayan (1), Rath al (1), Rathu heenati (2), Hondarawala (1) and Suduru samba (1) suggesting that they are date fixed accessions as explained by Chandraratna (1964) (Supplementary table 1 and 2).

\section{Comparison of total collection and mini core collection through regression analysis}

The standard deviation value of the distribution curve for DF of mini core collection indicated that wider DF variation is present there (Fig 3. A), although the total collection and DF of mini core collection were not normally distributed (Fig 3. B).

There are previous reports on development of linear regression models for relationships between important agronomic traits and morphological characters in rice collections (Chandraratne, 1964; Xie et al., 2013). During this study linear regression models could be developed for relationships between DF and PH, and DF and LL. Similar trends in regression models for DF and $\mathrm{PH}$, and DF and LL were detected in mini core collection as well indicating the close representation of DF variation in mini core collection (Fig 4).

\section{Varietal diversity of the total collection of traditional rice germplasm}

In a genetic analysis and development of a core collection of wild rice Oryza rufipogan, variation in genetic diversity among accessions had been determined based on both molecular markers and morphological characters which made information available for a greater genetic distance (Liu et al., 2015). Accessions of similar morphology were grouped in to individual clusters in Hierarchical cluster analysis (Supplementary table 1 and 2). Dahanala 6377, 2050 and 6739 appeared to be duplicates as they belong to the same cluster (cluster: 1) without significant differences in DF (82, 79 and 75) along with Dahanala 3131 (DF of 82) which is also related. In cluster 15, extreme DF and from different varieties were included: Sulai 3494 (DF of 179), Hondarawala 3521 (DF of 189), Hondarawala 6198 (DF of 141), Kotteyaran 3263 (DF of 82) and Mudukiriyal 6276 (DF of 139) belonged, which suggests that they can be flowering time extremes. DF of Kalu handiran 4535 and 4533 were 80 and 79 respectively suggesting them as duplicates. Pachchaperumal 5550, 5549 and 5548 took 62, 66 and 64 DF respectively in cluster 20 suggesting they are similar. Except Molligoda 4307, all the other 4 accessions of variety Molligoda were included in cluster 34 suggesting them as duplicates. Inclusion of Kalu handiran 4534 in the same cluster indicates the relatedness of genotype to variety Molligoda. Among 20 Murungakayan accessions, 6 (5612, 5611, 5610, 3257, 3489 , 6282) belonged to cluster 35 and could be duplicates. Suduru samba 3572 and 3594 should be duplicates as they belong to the same cluster (cluster: 37 ) with non-significant DF (99 and 94). Extreme DF of the collection was identified from Kurulu wee 3601 and Hondarawala 3528 as 175 and 186 days respectively. Kurulu thuda 4553 and 4555 belonged to the same cluster (cluster: 39) suggesting to be duplicates where Ahamba 4212 was also included. Meanwhile Kurulu thuda 4554 belonged to cluster 11 and Kurulu thuda 3722 belonged to cluster 04 , being very distinct from the first two accessions. Accessions of same variety exhibited both morphological and DF variation; Hondarawala, Sudu wee, Sulai and Mudukiriyal varieties comprise of distinctive accessions with distinctive DF and some accessions of Molligoda, Murungakayan and Pachchaperumal varieties appeared to be duplicates. Variations in pericarp color and lemma and palea color with 19 lemma and palea colors and 16 pericarp colors were observed (Team of NRC research project 12-129, 2014). Genetic basis for variations in pericarp color and lemma and palea color had been previously described by Chandrarathna (1964) and Sanghera et al. (2013). Among the seed characters of not- flowered accessions in core collection, Ma wee 4561 was an awn-less variety with white pericarp color which was different from other representative accessions of not- flowered dendrogram with awns and brown or light brown pericarp color. On the other hand, Hondarawala 4243 from flowered dendogram also possessed awns. As previously reported by Kush in 1997, Sri Lankan traditional rice is categorized into Oryza sativa indica which rarely possesses awns. The studied collection of Sri Lankan traditional rice germplasm indicates the genetic richness which needs to be explored though molecular experiments in future.

We believe that this mini core collection would be an efficient and reasonable collection for rice breeding, conservation and use for ecological adaptation studies, particularly for photoperiod responses of Sri Lankan traditional rice germplasm and may also be applicable for molecular genetic studies of Sri Lankan traditional rice germplasm.

\section{Materials and Methods}

\section{Rice accessions}

Three hundred eighty four rice accessions (Team of NRC research project 12-129, 2014) listed under 53 varieties were obtained from Plant Genetic Resources Center (PGRC) (Supplementary Table 1 and 2).

\section{Field experiment}

Rice accessions were grown at Rice Research and Development Institute, Batalagoda, Sri Lanka (in agro ecological zone, IL1 of latitude $7^{\circ} 29^{\prime} 12^{\prime \prime} \mathrm{N}$ and longitude $80^{\circ} 21^{\prime} 53^{\prime \prime} \mathrm{E}$ with a height of $137 \mathrm{~m}$ above mean sea level). Average temperature during the cropping season was around $32{ }^{\circ} \mathrm{C}$ and the soil was dark brown earth (DBE). Each replicate consisted of a plot of 9 plants in 3 rows: $20 \mathrm{~cm} \times 20 \mathrm{~cm}$ within and between rows and $40 \mathrm{~cm}$ between plots in a Completely Randomized Design (CRD) with 4 replicates. The 
Table 3. Sri Lankan traditional rice varieties and the number of accessions selected from each variety

\begin{tabular}{llc}
\hline & Variety name & Number of \\
accessions
\end{tabular}

experiment was carried out in the wet season during north eastern monsoon (Maha), 2012/2013 during which day length varies 11-11.5 hours in Sri Lanka. The seeds were sown in the upland nursery bed in December, 2012 with $15 \mathrm{~cm}$ spacing in between each accession. Seedlings were transplanted by 21-days. Fertilizer application, pest and disease management and weed control were according to the recommendation by the Department of Agriculture, Sri Lanka. The basal dressing of urea, triple super phosphate and murat of potash (of 50, 62.5 and 50 $\mathrm{kg} / \mathrm{ha}$ ) was applied during land preparation. Top dressings of $61.75,123.5$ and $123.5 \mathrm{~kg}$ / ha of urea were applied at 2 weeks, 5 weeks and 7 weeks of planting respectively. Manual weeding was done at regular intervals and the competition from weeds was kept minimal. Approximately permanent standing water level of $5 \mathrm{~cm}$ was maintained throughout the experiment. The experiment was terminated at the time of overlapping of following growing season in Sri Lanka (Yala), which is relatively dry long day season. South west monsoon rains are not experienced by this agro-ecological zone. Due to the lack of rainfall and irrigation problems, plant senescence was observed which lead to the decision of terminating the experiment.

\section{Evaluation of morphological traits}

Fifteen quantitative morphological characters; DF, CL, CN, CD, PL, GL, GW, LN, LL, LW, LiL, RL, SW and PW were recorded for the 344 flowered accessions within 210 days of experimental period. Nine quantitative morphological characters; $\mathrm{PH}, \mathrm{CN}, \mathrm{CD}, \mathrm{LN}$, LL, LW, LiL, RL and SW were recorded for the 39 not flowered accessions within 210 days of the experimental period.With respect to each character in a given accession, average value of replicates was considered for analysis. Data was collected at heading and at harvest of each variety. Measurement techniques were based on descriptor of rice published by the Team of NRC research project 12-129 (2014).

\section{Statistical analysis}

Data were analyzed using PCA and hierarchical cluster analysis through SPSS software (version 20), IBM, USA (Giraldo, et al., 2010; Liu, et al., 2015; Onomo, et al., 2006). PCA defined the patterns of variation between all the explanatory variables. PCA is a variable reduction procedure which comprises of PC's accounts for the avoidance of redundancy of observed variables (Table 1 and 2) (SAS Institute Inc., 2007).

Hierarchical Cluster analysis grouped and sorted the closely related accessions into clusters, using the PC scores of above the eigen value 1. Measure of dissimilarity was the Euclidean distance and the clustering method was Ward's linkage (Giraldo, et al., 2010; Liu, et al., 2015; Onomo, et al., 2006). The number of clusters was determined at the rescaled distance of 5 and 15 to allow subsequent statistical analysis (Fig 1 and 2; Supplementary table 1 and 2). Normal distribution curves and probability plots were developed for DF of total collection and mini core collection (Fig 3) and, a regression analysis (Fig 4) was carried out to evaluate the significant representation of selected mini core collection using Minitab software (version 14).

\section{Conclusion}

A mini core collection of 90 accessions was developed during non-inductive photoperiod season based on morphological and flowering time variation of minimum 56 to maximum 200+ days from a total of 384 accessions of Sri Lankan traditional rice collection (Oryza sativa indica). A similar trend in effect of flowering time on vegetative growth was observed in both mini core collection and total collection. 


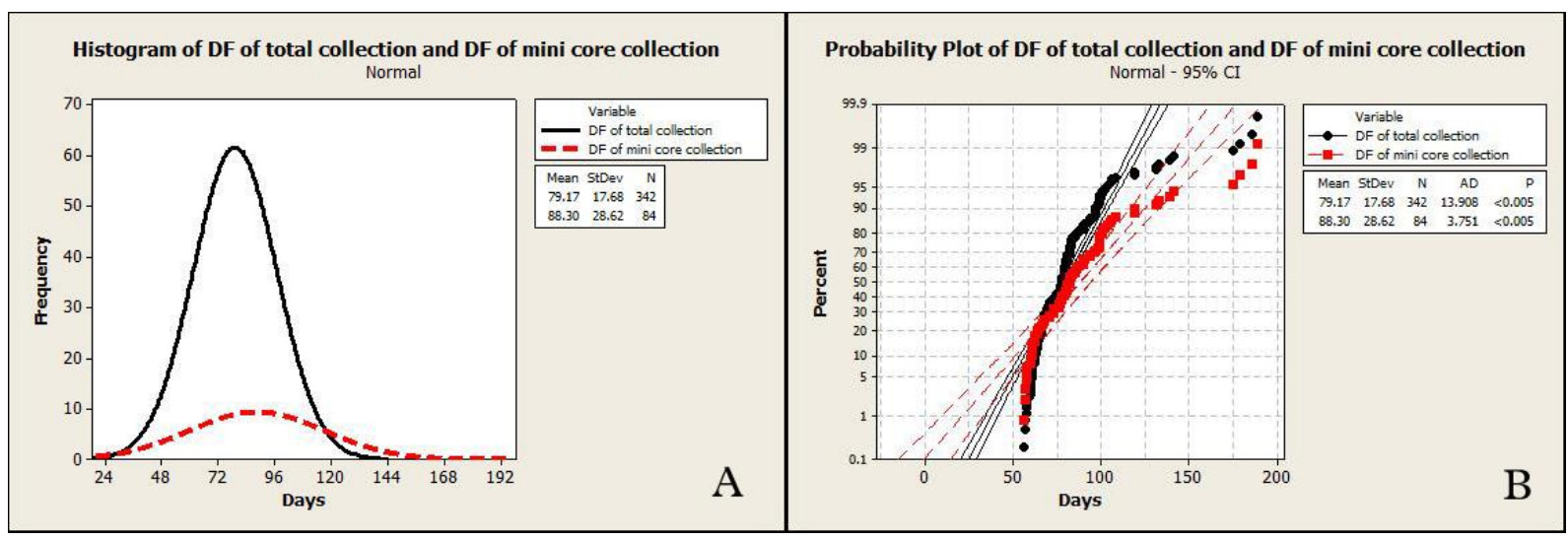

Fig 3 A. Normal distribution curves of DF of the total collection with contrast to the selected DF of mini core collection.B. Probability plots of DF of the total collection with contrast to the selected DF of mini core collection.

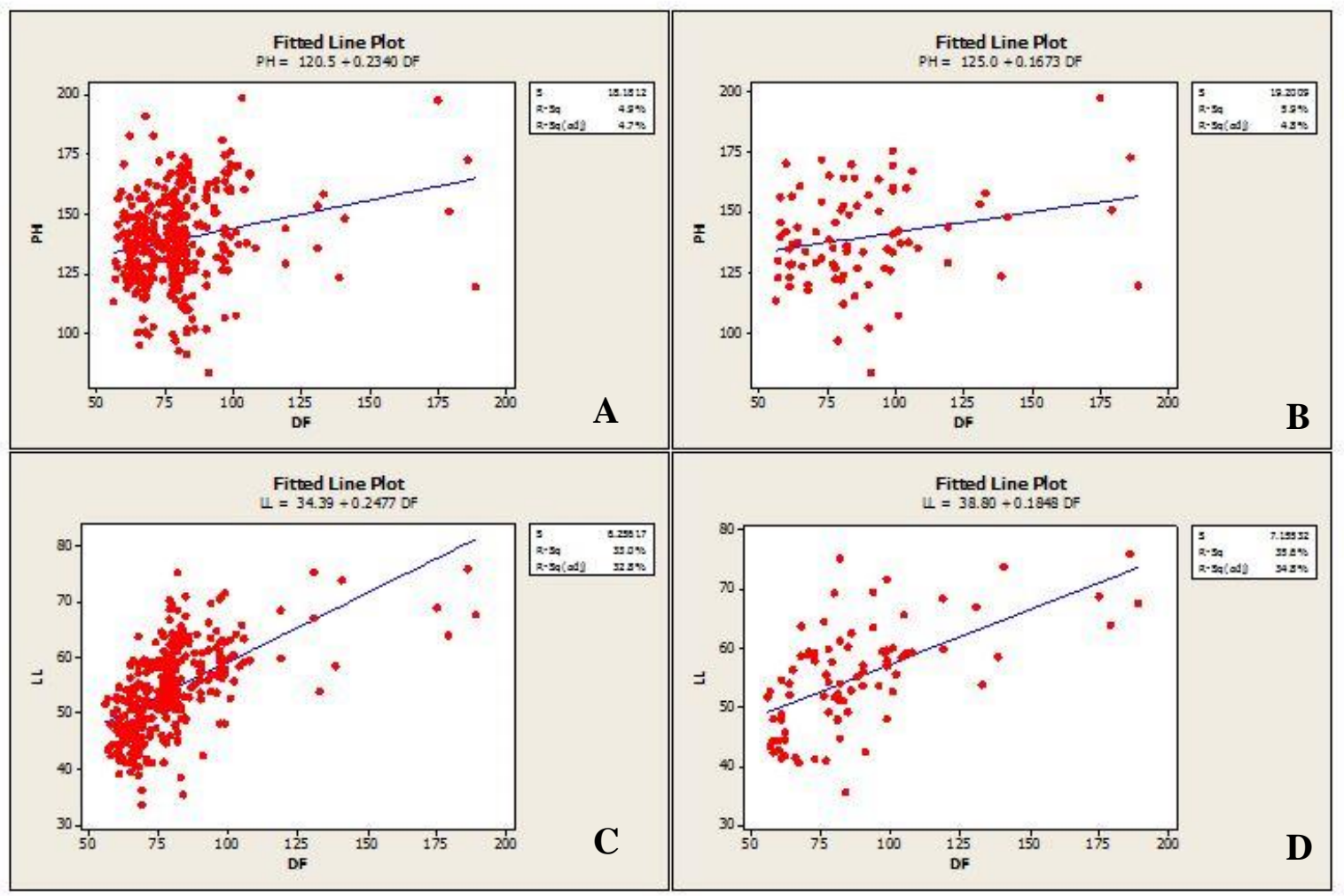

Fig 4. Regression analysis with association of DF on PH and LL for the 345 flowered accessions with contrast to the selected 85 accessions from flowered dendogram.

\section{Acknowledgement}

Authors acknowledge the National Research Council, Sri Lanka for funding the research through NRC 12-129 grant to SG and Plant Genetic Resources Center, Gannoruwa, Sri Lanka for seeds.

\section{References}

Ashfaq M, Khan AS, Khan SHU, Ahmad R (2012) Association of various morphological traits with yield and genetic divergence in rice (Oryza sativa). Int J Agr Biol. 14(1): 55-62.

Chang TT, Bardenas EA, (1965) Morphology and varietal characteristics of the rice plant. Int Rice Res Inst. P.O. Box 933, Manila, Philippines.
Chandraratna MF (1954) Photoperiod response in rice (Oryza sativa L.) I. effects on inflorescence initiation and emergence. New Phytol. 53(3): 397-405.

Chandraratna MF (1964) Genetics and breeding of rice. Longmans. Green and Co Ltd, 48 Grosvenor Street, London.

Chithranayana RD, Punyawardena BVR (2008) Identification of drought prone agro-ecological regions in Sri Lanka. J Natl Sci Found Sri. 36(2): 117-123.

De Costa WAJM, Wijeratne MAD, De Costa DM (2012) Identification of Sri Lankan rice varieties having osmotic and ionic stress tolerance during the first phase of salinity stress. J Natl Sci Found Sri. 40(3): 251-280.

Fageria NK (2014) Nitrogen Management in Crop Production. CRC Press. 
FAO Rice Market Monitor (2014) Trade and markets division. FAO. XV1I: 3. http://www.fao.org/3/ai4147e.pdf.

Gallagher KDW (1988) Effects of host plant resistance on the microevolution of the rice brown plant hopper Nilaparvata lugens (Stal) (Homoptera: Delphacidae). UC. Berkeley.

Giraldo E, López-Corrales M, Hormaza JI (2010) Selection of the most discriminating morphological qualitative variables for characterization of fig germplasm. J Am Soc Hortic Sci. 135(3): 240-249.

Herdt RW, Capule C (1983) Adoption, spread, and production impact of modern rice varieties in Asia. Int Rice Res Inst. P.O. Box 933, Manila, Philippines.

Hori K, Kataoka T, Miura K, Yamaguchi M, Saka N, Nakahara, Sunohara Y, Ebana K, Yano M (2012) Variation in heading date conceals quantitative trait loci for other traits of importance in breeding selection of rice. Breeding Sci. 62(3): 223.

International Rice Research Institute (1991) Rice germplasm; collecting, preservation, use. Int Rice Res Inst. P.O. Box 933, Manila, Philippines. ISBN 971-220026-4.

Irangani MKL, Shiratake Y (2013) Indigenous techniques used in rice cultivation in Sri Lanka: an analysis from an agricultural history perspective. Indian J Tradit Know. 12(4): 638-650.

Kato S, Kosaka H, Hara S (1928) On the affinity of rice varieties as shown by fertility of hybrid plants. Bull Sci Fac Agric Kyushu Univ. 3: 132-147

Khush GS (1997) Origin, dispersal, cultivation and variation of rice. Plant Mol Biol. Kluwer Academic Publishers, Belgium. 35: 25-34.

Lin Q, Wang D, Dong H, Gu S, Cheng Z, Gong J, Qin R, Jiang L, Li G, et al., Wan J (2012) Rice APC/CTE controls tillering by mediating the degradation of MONOCULM 1. Nat Commun. 3: 752.

Liu W, Shahid MQ, Bai L, Lu Z, Chen Y, Jiang L, Diao M, Liu X, Lu Y (2015) Evaluation of genetic diversity and development of a core collection of wild rice (Oryza rufipogon Griff.) populations in China. PLoS One. 10(12): e0145990.

Lu BR, Cai X, Xin J (2009) Efficient indica and japonica rice identification based on the InDel molecular method: Its implication in rice breeding and evolutionary research. Prog Nat Sci. 19(10): 12411252.

Manawadu L, Fernando N (2008) Climate Changes in Sri Lanka. Review. Journal of the University of Colombo, Sri Lanka. New Series. 1: 02.

Matsuo T (1952) Genecological studies on cultivated rice. Bull Nat Inst Agric Sci Jpn D. 3: 1-111.

Onomo PE, Niemenak N, Ndoumou DO (2006) Morphological variability of Cola acuminata ((Pal. De Beauv.) Schott et Endl.) germplasm in Cameroon. Pak J Biol Sci. 9: 398-403.

Pessarakli M (ed.) (2010) Handbook of plant and crop stress. CRC Press.

Punyawardena BVR, Bandara TMJ, Munasinghe MAK, NimalJayaratna Banda, Pushpakumara SMV (2003). Agro-ecological regions of Sri Lanka. NRMC, Department of Agriculture. Peradeniya, Sri Lanka.

Punyawardena BVR (2004) Technical report on the characterization of the agro-ecological context in which Farm Animal Genetic Resources (FAnGR) are found: Sri Lanka. Farm Animal Genetic Resources Project.
Rathnathunga EUU, Pushpakumari WHDU, Padukkage PDC, Dissanayake N, Fernando K, Rathnasiri PW, Senanayake G, Senaweera S, Geekiyanage S, (Team of NRC research project 12-129) (2014) Handbook on Varietal Diversity of Sri Lankan Traditional Rice (Oryza sativa L.). University of Ruhuna. Sri Lanka. ISBN: 978-955-0263-01-1.1: 89.

Ren J, Yu Y, Gao F, Zeng L, Lu X, Wu X, Yan W, Ren $G$ (2012) Analysis of genetic structure in the USDA rice mini core collection using the SQUAMOSA promoter-binding-like gene family. Rice Genomics and Genetics. 3: (1).

Sanghera GS, Kashyap SC, Parray GA (2013) Genetic variation for grain yield and related traits in temperate red rice (Oryza sativa L.) ecotypes. Not Sci Biol. 5(3): 400-406

Santra M, Matthews SB, Thompson HJ (2013) Development of a core collection of Triticum and Aegilopsspecies for improvement of wheat for activity against chronic diseases. Agriculture and Food Security. 2(1): 4.

SAS Institute Inc (2007) Chapter 1: Principal Components Analysis. http://support.sas.com/ publishing/pubcat/chaps/55129.pdf.

Studnicki M, Mądry W, Schmidt J (2013) Comparing the efficiency of sampling strategies to establish a representative in the phenotypic-based genetic diversity core collection of orchard grass (Dactylisglomerata L.). Czech J Genet Plant Breed. 49: 36-47.

Shakiba E, Eizenga GC (2014) Unraveling the secrets of rice wild species. In: Yan W, Bao J (ed) Rice: Germplasm, genetics, and improvement. Doi: 10, 58393.

Vergara BS, Chang TT (1985) The flowering response of the rice plant to photoperiod: a review of the literature. Int Rice Res Inst. P.O. Box 933, Manila, Philippines.

Wang $\mathrm{H}$, Velarde $\mathrm{O}$, Walisinghe $\mathrm{R}$, Herath RM, Rajapaksa D (2012) Pattern of varietal adoption and economics of rice production in Sri Lanka. In: Wang H, Pandey S, Velarde O, Hardy B (ed) Patterns of varietal adoption and economics of rice production in Asia. Int Rice Res Inst. P.O. Box 933, Manila, Philippines. 130.

Wijerathna Y, Kottearachchi N, Attanayaka D (2012) Assessment of inter and intra cultivar genetic and phenotypic variation in grain quality characteristics of Sri Lankan traditional aromatic rice (Oryza sativa L.). Trop Agric. 160.

Xie L, Tang S, Chen N, Luo J, Jiao G, Shao G, Wei X, Hu P (2013) Rice grain morphological characteristics correlate with grain weight and milling quality. Cereal Chem. 90(6): 587-593.

Xu C, Wang Y, Yu Y, Duan J, Liao Z, Xiong G, Meng X, Liu G, Qian Q, Li J (2012) Degradation of MONOCULM 1 by APC/CTAD1 regulates rice tillering. Nat Commun. 37: 50.

Yoshida S (1981) Growth and development of the rice plant. Fundamentals of rice crop science. Int Rice Res Inst. P.O. Box 933, Manila, Philippines. 1: 63.

Yoshida S (1983) Rice. In: W. H. Smith (ed) Symposium on potential productivity of field crops under different environments. Int Rice Res Inst. P.O. Box 933, Manila, Philippines. ISBN 971-104-114-6.

Zhang Y, Zhang X, Che Z, Wang L, Wei W, Li D (2012) Genetic diversity assessment of sesame core collection in China by phenotype and molecular markers and extraction of a mini-core collection. BMC Genet. 13(1): 102 . 